\title{
Effect of Na Content on the Physical Properties of $\mathrm{Ba}_{0.5} \mathrm{Sr}_{0.5} \mathrm{TiO}_{3}$ Powders
}

\author{
Tassanee Tubchareon, ${ }^{1}$ Soipatta Soisuwan, ${ }^{2}$ \\ Somchai Ratanathammaphan, ${ }^{3}$ and Piyasan Praserthdam ${ }^{1}$ \\ ${ }^{1}$ Center of Excellence on Catalysis and Catalytic Reaction Engineering, Department of Chemical Engineering, Faculty of Engineering, \\ Chulalongkorn University, Bangkok 10330, Thailand \\ ${ }^{2}$ Department of Chemical Engineering, Faculty of Engineering, Burapha University, Chonburi 20131, Thailand \\ ${ }^{3}$ Department of Electrical Engineering, Faculty of Engineering, Chulalongkorn University, Bangkok 10330, Thailand
}

Correspondence should be addressed to Piyasan Praserthdam; piyasan.p@chula.ac.th

Received 29 May 2013; Accepted 26 November 2013; Published 30 January 2014

Academic Editor: Jun Liu

Copyright (C) 2014 Tassanee Tubchareon et al. This is an open access article distributed under the Creative Commons Attribution License, which permits unrestricted use, distribution, and reproduction in any medium, provided the original work is properly cited.

The different $\mathrm{Na}$ contents $(0 \leq \mathrm{Na} \leq 0.35$, based on mole of $\mathrm{NaOH})$ of doped $\mathrm{Ba}_{0.5} \mathrm{Sr}_{0.5} \mathrm{TiO}_{3}$ (BST) powders synthesized via solgel process were studied. The substitution of $\mathrm{Na}^{+}$ions into a partial A-site of BST powders provided the reduction in vacancy defects as confirmed by electron paramagnetic resonance (EPR) and UV-visible spectroscopy. Photoluminescence (PL) spectra appeared in violet, blue, and green emissions. The phase structure, oxygen deficiency, and titanium deficiency of BST powders were further investigated as a function of $\mathrm{Na}$ content. X-ray diffraction (XRD) result was found that low $\mathrm{Na}$ content $(0 \leq \mathrm{Na}$ $\leq 0.15$ ) exhibited the tetragonal structure, while it was transformed to the cubic phase when high Na content. Moreover, X-ray photoelectron spectroscopy (XPS) result revealed that the partial oxidation of $\mathrm{Ti}^{3+}$ ions to $\mathrm{Ti}^{4+}$ ions was observed at $\mathrm{Na}$ content lower than 0.05 mole, while more addition of $\mathrm{Na}$ content resulted in the increasing of the oxygen and the titanium deficiency. Furthermore, the result indicated the oxygen deficiency significantly formed at the A-site of Sr atoms more than that of Ba atoms.

\section{Introduction}

The $\mathrm{Ba}_{0.5} \mathrm{Sr}_{0.5} \mathrm{TiO}_{3}$ (BST) powders exhibit excellent electrical properties and have been extensively used in various electronic applications such as semiconductor, dynamic random access memory (DRAM), ceramic capacitors, pyroelectric sensors, and microwave devices $[1,2]$.

The metal doped titanate-based perovskite has been widely reported such as $\mathrm{Na}^{+}[3], \mathrm{K}^{+}[3], \mathrm{Mg}^{2+}[3-5], \mathrm{Ca}^{2+}[4]$, $\mathrm{Ni}^{2+}[5,6], \mathrm{Cu}^{2+}[7], \mathrm{Pb}^{2+}[8,9], \mathrm{Ga}^{3+}[3], \mathrm{Fe}^{3+}[5,6], \mathrm{Pr}^{3+}$ [6], $\mathrm{La}^{3+}[6,10]$, and $\mathrm{Nd}^{3+}$ [11]. The metal doped perovskite materials can substitute into A- and/or B-site, relying on the ionic radii of metal dopant. Typically, acceptor-dopant is the creation of vacancy site, that is, cation vacancy and anion vacancy. The oxygen vacancy is a kind of anion vacancy that can be generated as well as the recombination of electrons and holes defect [12]. Moreover, it plays an important role in the structurally order-disorder of perovskite materials [13].
In our previous study, it was found that the oxygen deficiency significantly affected the A-site of $\mathrm{Sr}$ atoms more than that of $\mathrm{Ba}$ atoms and the modified A/B-site of BST powders influenced the phase structure [3]. Therefore, this work investigates the modified A-site of BST powders under the study of the influence of $\mathrm{Na}$ content on the physical properties of BST powders. Since the solid state technique of preparation has met a restriction concerning high temperature reaction and nonhomogeneity, lower temperature preparation is required. Hence, the sol-gel technique has been introduced in our experiments. The Na-doped BST powders were characterized by TG, XRD, XPS, PL, UV-vis, and EPR.

\section{Experimental}

2.1. Material Synthesis. All the starting materials used in this work are commercially available and are used 
without further purification. Barium hydroxide octahydrate $\left[\mathrm{Ba}(\mathrm{OH})_{2} \cdot 8 \mathrm{H}_{2} \mathrm{O}\right](98 \%$, Aldrich), strontium nitrate [Sr $\left.\left(\mathrm{NO}_{3}\right)_{2}\right]$ (99\%, Aldrich), titanium (IV) isopropoxide $\left[\mathrm{C}_{12} \mathrm{H}_{28} \mathrm{O}_{4} \mathrm{Ti}\right]$ (97\%, Aldrich), sodium hydroxide [NaOH] (Merck), and deionized water were used as the starting materials for BST powders synthesis by the sol-gel method. The starting solution $(50 \mathrm{~mL})$ contained the $\mathrm{Ba}+\mathrm{Sr}$ precursors and Ti precursor at $(\mathrm{Ba}+\mathrm{Sr}):$ Ti ratio of $1: 1$, and $\mathrm{Ba}: \mathrm{Sr}$ ratio is equal to $0.5: 0.5$. To concentration of sodium hydroxy doped BST powders were to be at $0,0.025,0.05,0.15,0.25$, and 0.35 , respectively. The abbreviations of BST powders in this work are described as BST $x$, where $x$ is mole of sodium hydroxide doped BST powders.

In preparation solution, the raw materials of $\mathrm{Ba}, \mathrm{Sr}$, and $\mathrm{Na}$ precursor were dissolved in deionized water, and then the homogeneous solution was stirred for $1 \mathrm{~h}$ at mild heating to completely dissolve the metallic precursor. The solution was then stirred at room temperature for $2 \mathrm{~h}$, and then Ti precursor was continuously added drop-wise and continuously stirred until a white precipitate appeared. The BST solution was then stirred overnight at room temperature to completely mix. The solution was washed three times in methanol and the as-synthesized BST product was finally dried in an oven at $110^{\circ} \mathrm{C}$ and calcined in stagnant air at $750^{\circ} \mathrm{C}$ for $5 \mathrm{~h}$.

2.2. Materials Characterizations. All samples characterizations were measured at room temperature. The assynthesized (dried-gel) BST powders were characterized by thermogravimetric analyzer (TG). The thermal analysis was performed by SDT Q600 instrument under air flow of $400 \mathrm{~mL} \mathrm{~min}{ }^{-1}$ and heating rate of $5^{\circ} \mathrm{C} \mathrm{min}^{-1}$. The calcinations BST powders were examined by XRD, XPS, PL, UV-vis, and EPR. X-ray diffraction (XRD) was performed by SEIMENS D5000 using $\mathrm{CuK}_{\alpha}$ and Ni filter. X-ray photoelectron spectroscopy (XPS) was examined by AMICUS with $\mathrm{MgK}_{\alpha} \mathrm{X}$ ray source. The $\mathrm{Cls}$ is used as reference peak at $285.0 \mathrm{eV}$. Photoluminescence (PL) was measured by Perkin Elmer LS 55 and was excited by Xenon lamp source at $325 \mathrm{~nm}$. The ultraviolet-visible spectroscopy (UV-vis) was examined with Perkin Elmer LAMDA 650 which was measured between 200 and $900 \mathrm{~nm}$. The electron paramagnetic resonance (EPR) was studied by JEOL model JES-RE2X with DPPH used for $g$ value calibration.

\section{Results and Discussions}

3.1. Effect of $\mathrm{Na}$ Contents on the Thermal Properties of BST Powders. Thermal analysis was carried out under air flow in order to investigate the thermal properties of dried-gel with various $\mathrm{Na}$ contents as shown in Figure 1.

The two stepwise losses of weight exhibited at temperatures $400^{\circ} \mathrm{C}$ and $600^{\circ} \mathrm{C}$ for $\mathrm{Na}$ contents up to 0.15 mole, that is, BST0.025, BST0.05, and BST0.15. This can be explained that the physical and the chemical desorption of water were presented at the temperature below $400^{\circ} \mathrm{C}$ [14], in which the carbonate species were possibly decomposed at higher temperature in range of $400-600^{\circ} \mathrm{C}[15,16]$, and no

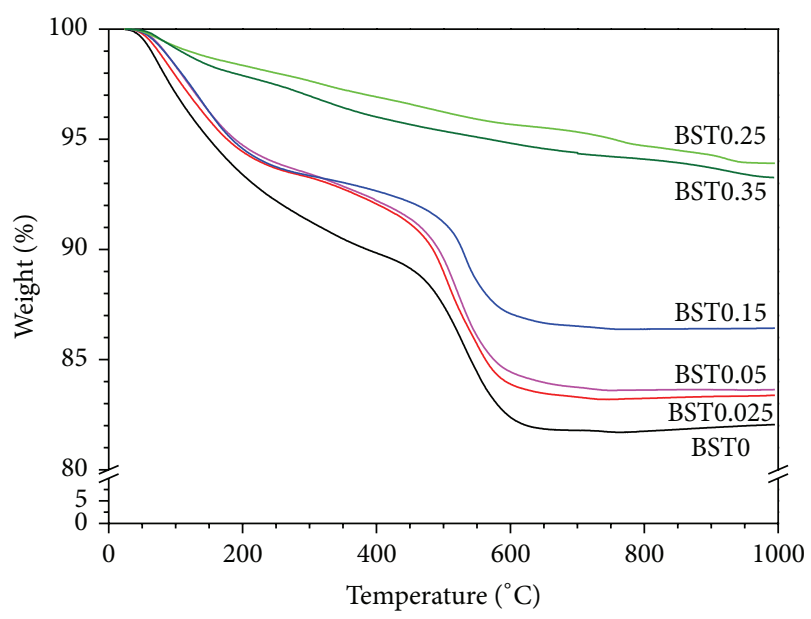

FIGURE 1: The TG curves of dried-gel BST powders with various $\mathrm{Na}$ contents.

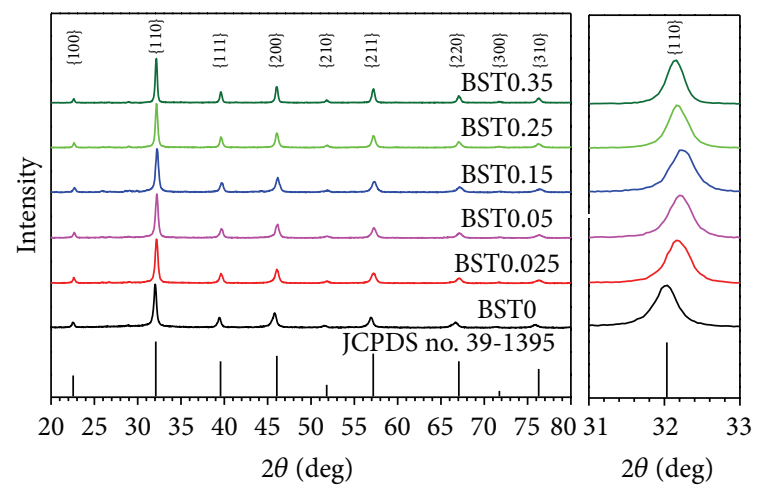

FIgURE 2: The XRD patterns of BST powders with various $\mathrm{Na}$ contents.

significant weight changes were eventually observed after the temperature $650^{\circ} \mathrm{C}$. In case of $\mathrm{Na}$ contents up to 0.25 and 0.35 moles (BST0.25 and BST0.35), the differences in thermal decomposition patterns which possessed constant loss rate in the experimental range of room temperature to $1000^{\circ} \mathrm{C}$ are apparently presented in Figure 1. However the thermal response of dried-gel for both patterns did not show the significant effect on the formation of perovskite crystalline structure as will be mention later.

3.2. Effect of $\mathrm{Na}$ Contents on the Phase Structure of BST Powders. The structure of BST powders was achieved via the sol-gel process as depicted in Figure 2. The incorporation of the stranger $\mathrm{Na}^{+}$ions in BST structure was ascribed to the shifted position of the main peak $\{110\}$. Moreover, the substitution of $\mathrm{Na}^{+}$ions into A-site of BST crystalline can be verified by the reduction in the lattice parameter [3] as illustrated in Table 1. The decreasing of lattice parameter probably occurred since the smaller ionic radii of $\mathrm{Na}^{+}$ion $(0.139 \mathrm{~nm})$ were partially occupied in the A-site of $\mathrm{Ba}^{2+}$ ion $(0.161 \mathrm{~nm})$ and/or $\mathrm{Sr}^{2+}$ ion $(0.144 \mathrm{~nm})$. Consequently, the phase structures of BST perovskite were observed as a 
TABLE 1: Crystallite size, lattice parameter, and indirect band gap of BST powders with various Na contents.

\begin{tabular}{lcccc}
\hline \multirow{2}{*}{ Sample } & Crystallite size $(\mathrm{nm})$ & \multicolumn{2}{c}{ Lattice parameter $(\mathrm{nm})$} & Indirect band gap $(\mathrm{eV})$ \\
\hline BST0 & 30 & 0.3954 & - & 2.80 \\
BST0.025 & 29 & 0.3934 & 0.3950 & 3.15 \\
BST0.05 & 30 & 0.3931 & 0.3946 & 2.90 \\
BST0.15 & 28 & 0.3927 & 0.3944 & 3.18 \\
BST0.25 & 40 & 0.3934 & - & 3.20 \\
BST0.35 & 54 & 0.3939 & - & 2.90 \\
\hline
\end{tabular}

function of Na contents. The XRD patterns of BST0 showed the cubic structure of $\mathrm{Ba}_{0.5} \mathrm{Sr}_{0.5} \mathrm{TiO}_{3}$ which referred to Joint Committee on Powder Diffraction Standards (JCPDS) card number 39-1395. Considering low Na content (0-0.15 mole), BST0.025, BST0.05, and BST0.15 showed slightly asymmetric peak of $\{200\}$, indicating the presence of the tetragonal distortion $[3,17]$. As a result, it was evident that the tetragonality (c/a ratio) of BST powders was approximately 1.004 . Thus, the $\mathrm{B}$-site cation shifted away from the center of $\mathrm{BO}_{6}$ octahedral due to the local charge imbalance, resulting in the tetragonal distortion [18]. On the other hand, at high Na content, that is, BST0.25 and BST0.35, the $\mathrm{Na}^{+}$ions were randomly occupied into the A-site of BST powders and the $\mathrm{BO}_{6}$ octahedral distortion was therefore decreased. As the result of the local charge balance, thus causing the phase transformation from tetragonal to cubic [18].

3.3. Effect of Na Contents on the Vacancy Defects of BST Powders. The ordered structure of titanate-based perovskite can be explained as $\left(\mathrm{TiO}_{6}\right)-\left(\mathrm{TiO}_{6-x}\right)$ clusters, in which their cation and vacant of A- or B-site are arranged in the order that is close to the perfect lattice crystalline. These clusters are only significant when the absences of A- or B-site of metal vacancies occurred, whereas the disordered structure suggests that the metal-dopant is randomly distributed in the perovskite structure. The disordered structure can be explained as $\left(\mathrm{TiO}_{5}-\mathrm{V}_{\mathrm{O}}{ }^{\mathrm{Z}}\right)-\left(\mathrm{TiO}_{6}\right)$ clusters where the oxygen vacancies can possibly occur in three states: (i) neutral oxygen vacancy $\left(\mathrm{V}_{\mathrm{O}}{ }^{\mathrm{X}}\right)$, (ii) singly ionized oxygen vacancy $\left(\mathrm{V}_{\mathrm{O}}{ }^{*}\right)$, and (iii) fully ionized oxygen vacancy $\left(\mathrm{V}_{\mathrm{O}}{ }^{*}\right)$. Moreover, the degree of the ordered-disordered structure can be interpreted by the optical absorption edge [19]. In Figure 3, it can be observed that the absorbance spectra dramatically decreased at the wavelength of $\mathrm{ca} .380 \mathrm{~nm}$. The indirect band gap of Nadoped BST powders was slightly higher than the BST0 as seen in Table 1. The increase in the band gap was attributed to the reduction in the lattice defect [20] and the vacancies site [21].

Furthermore, the ordered-disordered structure was also examined by the photoluminescence behavior. According to typically the PL light emissions [22-25], the shallow defect indicated more structural order of perovskite materials, showing in violet and blue light emissions. Contrarily, the deep defect pointed to the structural disorder, presenting in green, yellow, orange, and red light emissions. Figure 4 determines the PL spectra of BST powders with various $\mathrm{Na}$ contents. In the violet light emissions, the first peak is

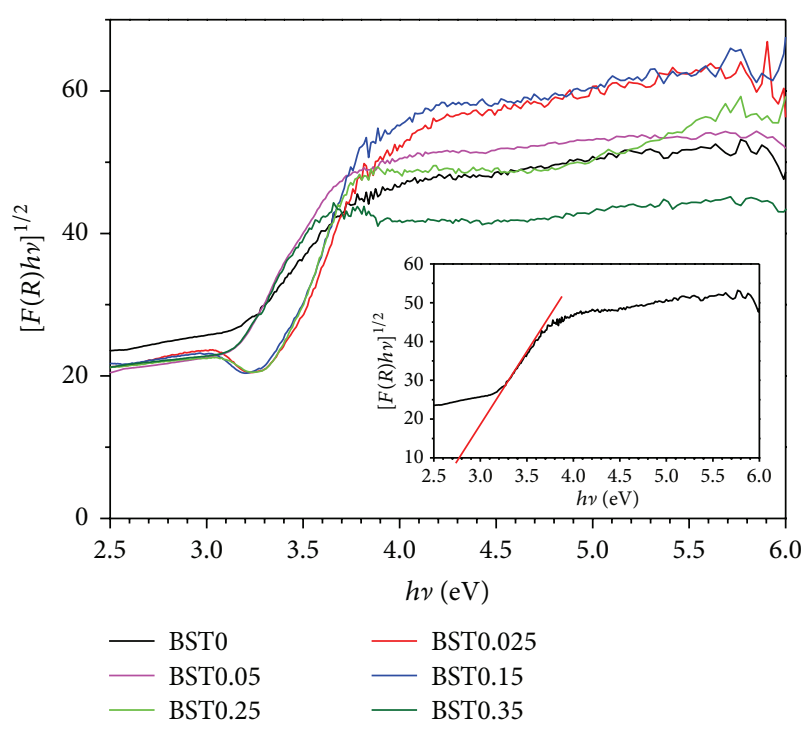

FIGURE 3: The UV-vis spectra of BST powders with various $\mathrm{Na}$ contents.

attributed to the optical band gap of BST powders $[3,26]$. This peak rather agreed with the optical band gap of UVvis result. The second peak at $2.95 \mathrm{eV}$ was assigned to the electron transferring in $\mathrm{TiO}_{6}[21,27]$. The third peak emitting in the blue light $(2.80 \mathrm{eV})$ was related to the fully ionized oxygen vacancy $\left(\mathrm{V}_{\mathrm{O}}{ }^{*}\right)[28,29]$. Furthermore, for the green light emissions, the fourth peak $(2.55 \mathrm{eV})$ corresponded to the charge-transfer of singly ionized oxygen vacancy $\left(\mathrm{V}_{\mathrm{O}}{ }^{\cdot}\right)$ $[21,27,30]$ and the last one (at $2.33 \mathrm{eV}$ ) was assigned to the charge-transfer vibronic excitons (CTVE) of Ti-O-Ti in perovskite $[28,30]$.

In addition, the electron paramagnetic resonance (EPR) is one of the most widely used techniques to investigate the defect complex with one unpaired electron. Figure 5 illustrates the EPR spectra of BST powders with different $\mathrm{Na}$ contents. It can be clearly seen that BST0 exhibited the strongest intensity of the EPR signal at the $g$ value of 2.004, while other BST powders modified by $\mathrm{Na}^{+}$ions obviously provided the decreased $g$-signal intensity. This signal was associated with the titanium vacancy, that is, $\mathrm{V}_{\mathrm{Ti}}{ }^{\prime}$ or $\mathrm{V}_{\mathrm{Ti}}{ }^{\prime \prime \prime}[31,32]$. The result was in a good agreement with our previous work [3], claiming that the $\mathrm{Na}^{+}$ions which modified BST powder caused the decrease in the $g$-signal intensities. Moreover, low intensity of EPR signal indicated 


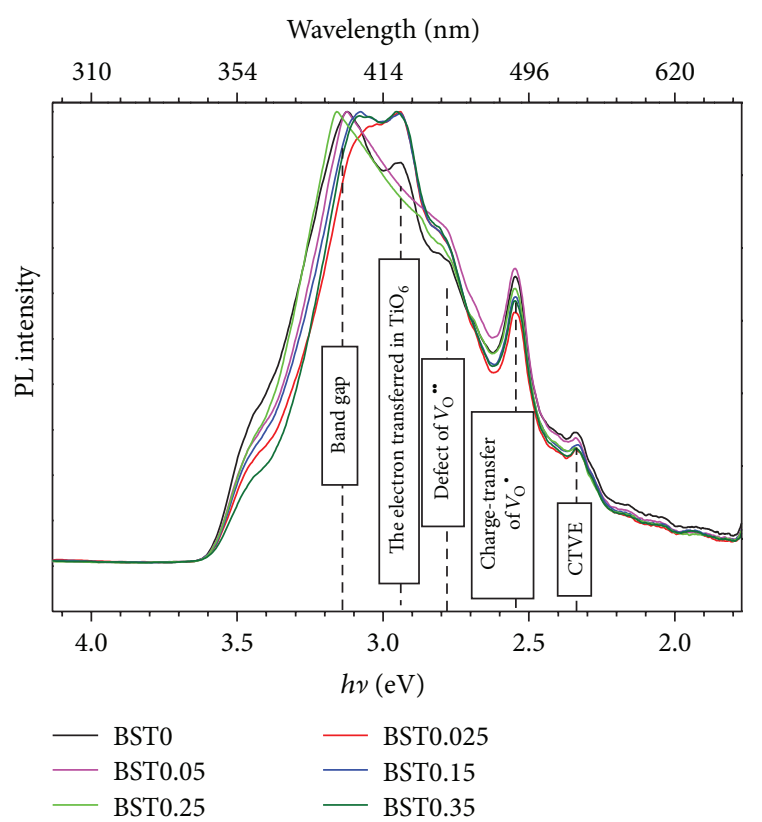

FIgURE 4: The PL spectra of BST powders with various Na contents.

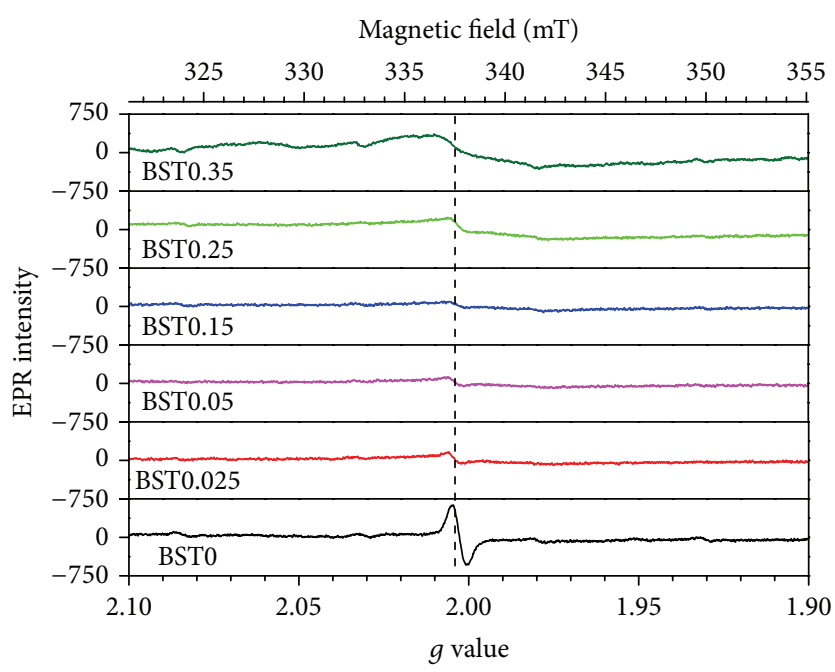

FIGURE 5: The EPR signal of BST powders with various Na contents.

lower content of defect. This result corresponded to the UVvis result. Regarding, higher in doping level, the symmetry of EPR spectra peak obviously decreased, relying on the $\mathrm{Na}$ contents.

In this work, all samples were observed the green emissions in PL spectra. It can be implied that the formation of oxygen deficiency reasonably occurred in BST powders. Therefore, it was necessary to consider the amount of oxygen on the surface by means of XPS. The deconvolution of $\mathrm{O} 1 \mathrm{~s}$ and Ti $2 p$ with Gaussian function for all samples is presented in Figures 6 and 7, respectively. According to the curve fitting analysis, the $\mathrm{O} 1 \mathrm{~s}$ spectra peak was composed of three oxygen species. The first species observed at ca. 528.7 and $529.8 \mathrm{eV}$ [33-35] was attributed to the lattice oxygen $\left(\mathrm{O}_{\mathrm{L}}\right)$. Secondly,

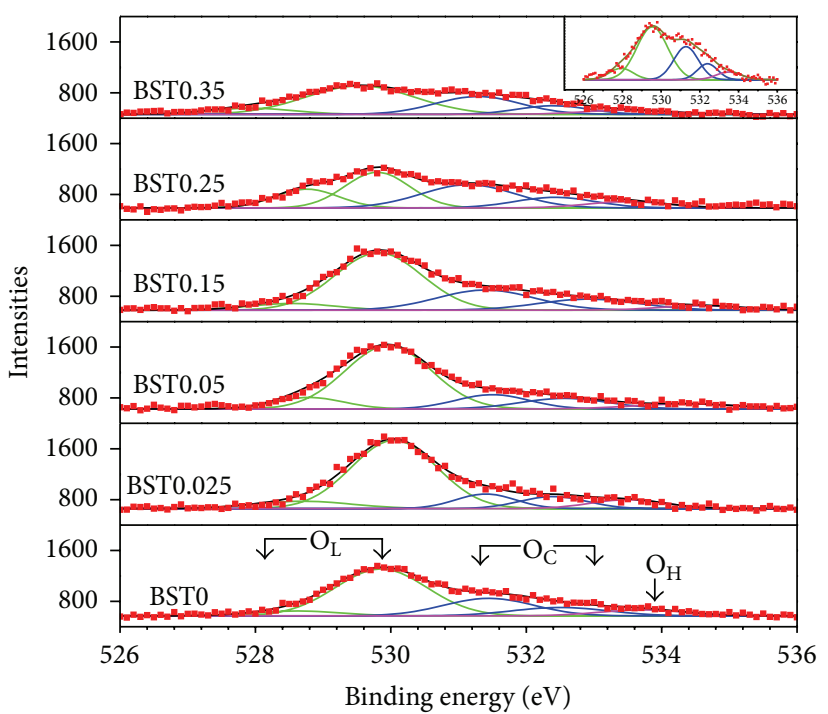

FIGURE 6: The fitting XPS spectra of $\mathrm{O}$ 1s deconvolution with Gaussian function.

the chemisorption oxygen $\left(\mathrm{O}_{\mathrm{C}}\right)$ appeared at ca. 531.4 and $532.4 \mathrm{eV}[33,34]$. For the last one, the oxygen in hydroxyl $\left(\mathrm{O}_{\mathrm{H}}\right)$, observed at about $533.5 \mathrm{eV}[34]$. Moreover, the presence of $\mathrm{Ti}^{4+}$ ion exhibited the XPS spectra of two positions located at ca. 458.5 and $464.3 \mathrm{eV}$, while the spectra of the defect $\mathrm{Ti}^{3+}$ ion that might occur via the loss of oxygen site were apparently found at ca. 457.8 and $462.4 \mathrm{eV}[36,37]$. From Table 2, it is clearly revealed that low Na contents (BST0.025 and BST0.05) suppressed both of the $\left(\mathrm{O}_{\mathrm{C}}+\mathrm{O}_{\mathrm{H}}\right) / \mathrm{O}_{\mathrm{L}}$ ratio and the $\mathrm{Ti}^{3+} / \mathrm{Ti}^{4+}$ ratio. It is indicated that the oxygen and the titanium deficient formations reduced due to the occurrence of the oxidation of titanium leading to the change in the valence state from $\mathrm{Ti}^{3+}$ to $\mathrm{Ti}^{4+}$ ion. At higher $\mathrm{Na}$ contents (BST0.15, BST0.25, and BST0.35), the increase in the oxygen and the titanium deficient formation was achieved because of the increase of the chemisorption oxygen.

As mentioned above, the B-site cation was fluctuated in titanium ions as a result of oxygen vacancies. In order to provide a further insight into the fluctuation in A-site, the surface chemistry of $\mathrm{Sr} 3 \mathrm{~d}$ and $\mathrm{Ba} 3 \mathrm{~d}$ was essentially investigated. From the curve fitting of $\mathrm{Sr} 3 \mathrm{~d}$ spectra peak, it was found that the Sr 3d consisted of two strontium species. The SrO oxide appeared at ca. 132.4 and $134.4 \mathrm{eV}$, while the $\mathrm{SrO}_{1-\delta}$ suboxide was observed at about 133.2 and $135.1 \mathrm{eV}$ [38], as seen in Figure 8. Figure 9 presented two barium species, that is, the $\mathrm{BaO}$ oxide was found at $\mathrm{ca} .778 .7$ and $794.2 \mathrm{eV}$, while the $\mathrm{BaO}_{1-\delta}$ suboxide was observed at about 780.2 and $795.2 \mathrm{eV}$ [39-41]. As reported in Table 2, it was revealed that Na-doped BST powders with increasing the $\mathrm{Na}$ contents affected the increased $\mathrm{SrO}_{1-\delta} / \mathrm{SrO}$ ratio, whereas decreased $\mathrm{BaO}_{1-\delta} / \mathrm{BaO}$ ratio was obtained. The oxygen deficiency significantly affected the A-site of Sr atoms more than that of $\mathrm{Ba}$ atoms [3]. This was probably due to the strength of $\mathrm{Ba}-\mathrm{O}$ chemical bonds $(561.9 \pm 13.4 \mathrm{~kJ} / \mathrm{mol})$ which are higher than those of $\mathrm{O}-\mathrm{Sr}$ bonds $(426 \pm 6.3 \mathrm{~kJ} / \mathrm{mol})$ [42]. 
TABLE 2: The atomic ratio calculations of $\mathrm{O}$ 1s, Ti 2p, Sr 3d, and Ba $3 \mathrm{~d}$.

\begin{tabular}{lcccc}
\hline Samples & $\left(\mathrm{O}_{\mathrm{C}}+\mathrm{O}_{\mathrm{H}}\right) / \mathrm{O}_{\mathrm{L}}$ & $\mathrm{Ti}^{3+} / \mathrm{Ti}^{4+}$ & $\mathrm{SrO}_{1-\delta} / \mathrm{SrO}$ & $\mathrm{BaO}_{1-\delta} / \mathrm{BaO}^{2}$ \\
\hline BST0 & 0.56 & 0.22 & 0.62 & 0.82 \\
BST0.025 & 0.36 & 0.17 & 0.87 & 0.68 \\
BST0.05 & 0.40 & 0.15 & 0.73 & 0.56 \\
BST0.15 & 0.56 & 0.22 & 1.08 & 0.59 \\
BST0.25 & 0.63 & 0.26 & 1.05 & 0.52 \\
BST0.35 & 0.69 & 0.22 & & 0.57 \\
\hline
\end{tabular}

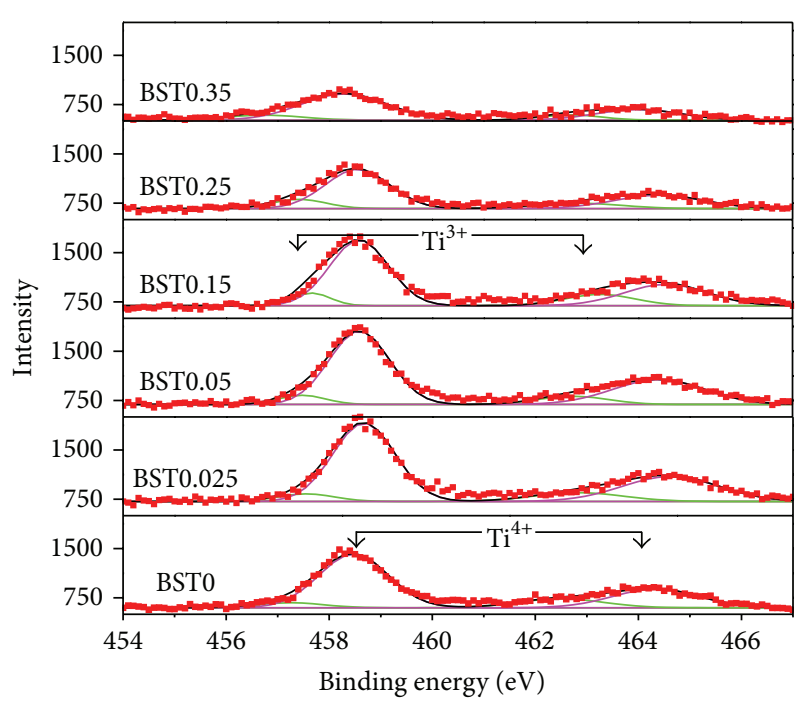

FIgURE 7: The fitting XPS spectra of Ti $2 p$ deconvolution with Gaussian function.

\section{Conclusions}

The various moles of sodium hydroxide $(0,0.025,0.05$, $0.15,0.25$, and 0.35 ) doped BST powders were investigated. The $\mathrm{Na}^{+}$ions were partially substituted into A-site of BST powders. It was revealed that the Na-doped BST powders obviously caused the decreased weight loss and titanium vacancy defects. The five peaks of PL spectra were found to be at $3.15,2.95,2.80,2.55$, and $2.33 \mathrm{eV}$. These can be assigned to the band gap, the electron transfer in $\mathrm{TiO}_{6}$, the fully ionized oxygen vacancy $\left(\mathrm{V}_{\mathrm{O}}{ }^{\bullet}\right)$, the charge-transfer of singly ionized oxygen vacancy $\left(\mathrm{V}_{\mathrm{O}}{ }^{\bullet}\right)$, and the charge-transfer vibronic excitons in BST powders, respectively. The presence of $\mathrm{Na}$ content affected the phase structure. At low $\mathrm{Na}$ content (0-0.15), the appearance of tetragonal structure was observed because of slightly asymmetric peak of $\{200\}$ from XRD pattern. Besides, at higher in $\mathrm{Na}$ content, the $\mathrm{Na}^{+}$ions were randomly occupied into the A-site of BST powder, leading to the phase structure evolved from tetragonal to cubic structure. Moreover, the oxygen and the titanium deficiency were dependent on the $\mathrm{Na}$ content. At low $\mathrm{Na}$ content (00.05), both of the oxygen and the titanium deficiency were reduced due to the oxidation of a small fraction of $\mathrm{Ti}^{3+}$ ion to $\mathrm{Ti}^{4+}$ ion, whereas those increased with more addition of $\mathrm{Na}$ content. Furthermore, this work can confirm that the $\mathrm{Sr}-\mathrm{O}$ was lower in the strength of chemical bond than the $\mathrm{Ba}-\mathrm{O}$,

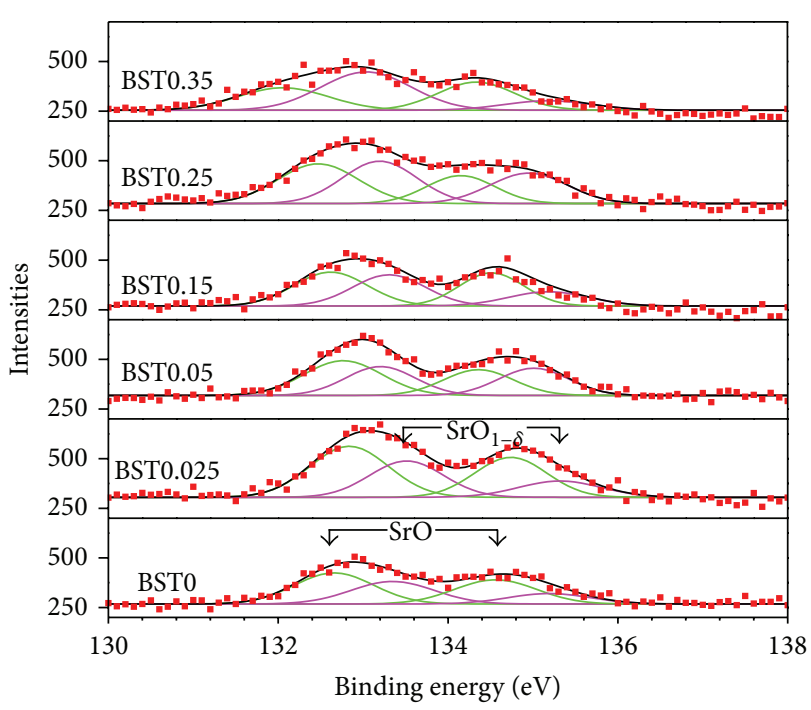

FIgURE 8: The fitting XPS spectra of Sr 3d deconvolution with Gaussian function.

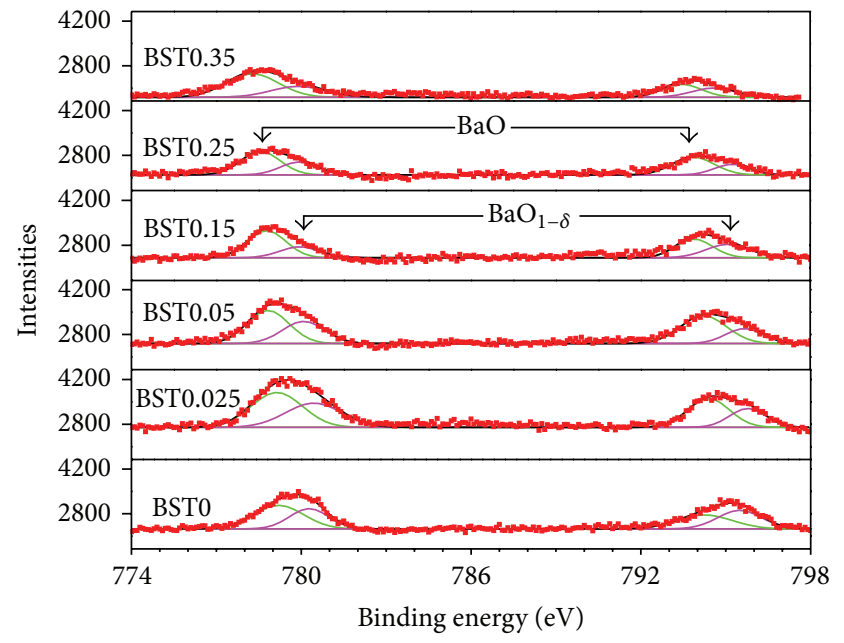

FIGURE 9: The fitting XPS spectra of $\mathrm{Ba} 3 \mathrm{~d}$ deconvolution with Gaussian function.

indicating the A-site of $\mathrm{Sr}$ atom formed the oxygen deficient more than $\mathrm{A}$-site of $\mathrm{Ba}$ atom. 


\section{Conflict of Interests}

The authors declare that there is no conflict of interests regarding the publication of this paper.

\section{Acknowledgments}

The financial support from Mektec Manufacturing Corporation (Thailand) Ltd. and The Ratchadaphiseksomphot Endowment Fund of Chulalongkorn University (RES5605300086-AM) are greatly appreciated.

\section{References}

[1] Y. B. Khollam, S. B. Deshpande, H. S. Potdar, S. V. Bhoraskar, S. R. Sainkar, and S. K. Date, "Simple oxalate precursor route for the preparation of barium-strontium titanate: $\mathrm{Ba}_{1-x} \mathrm{Sr}_{x} \mathrm{TiO}_{3}$ powders," Materials Characterization, vol. 54, no. 1, pp. 63-74, 2005.

[2] C. Mao, X. Dong, T. Zeng, H. Chen, and F. Cao, "Nonhydrolytic sol-gel synthesis and dielectric properties of ultrafine-grained and homogenized $\mathrm{Ba}_{0.70} \mathrm{Sr}_{0.30} \mathrm{TiO}_{3}$," Ceramics International, vol. 34, no. 1, pp. 45-49, 2008.

[3] T. Tubchareon, S. Soisuwan, S. Ratanathammaphan, and P. Praserthdam, "Effect of Na-, K-, Mg-, and Ga dopants in A/Bsites on the optical band gap and photoluminescence behavior of $\left[\mathrm{Ba}_{0.5} \mathrm{Sr}_{0.5}\right] \mathrm{TiO}_{3}$ powders," Journal of Luminescence, vol. 142, pp. 75-80, 2013.

[4] Y. Li, X. Yao, and L. Zhang, "Dielectric properties and microstructure of magnesium-doped $\mathrm{Ba}_{1+k}\left(\mathrm{Ti}_{1-x} \mathrm{Ca}_{x}\right) \mathrm{O}_{3-x+k}$ ceramics," Ceramics International, vol. 30, no. 7, pp. 1283-1287, 2004.

[5] X. Zhou, H. Geßwein, M. Sazegar et al., "Characterization of metal $(\mathrm{Fe}, \mathrm{Co}, \mathrm{Ni}, \mathrm{Cu})$ and fluorine codoped barium strontium titanate thick-films for microwave applications," Journal of Electroceramics, vol. 24, no. 4, pp. 345-354, 2010.

[6] M. T. Buscaglia, V. Buscaglia, M. Viviani, P. Nanni, and M. Hanuskova, "Influence of foreign ions on the crystal structure of $\mathrm{BaTiO}_{3}$," Journal of the European Ceramic Society, vol. 20, no. 12, pp. 1997-2007, 2000.

[7] H. T. Langhammer, T. Müller, R. Böttcher, and H. P. Abicht, "Crystal structure and related properties of copper-doped barium titanate ceramics," Solid State Sciences, vol. 5, no. 7, pp. 965-971, 2003.

[8] C. R. Gautam, D. Kumar, and O. Parkash, "Crystallization behavior and microstructural analysis of lead-rich $\left(\mathrm{Pb}_{x} \mathrm{Sr}_{1-x}\right)$ $\mathrm{TiO}_{3}$ glass ceramics containing 1mole $\mathrm{La}_{2} \mathrm{O}_{3}$, Advances in Materials Science and Engineering, vol. 2011, Article ID 402376, 11 pages, 2011.

[9] C. R. Gautam, D. Kumar, and O. Parkash, "Crystallization behavior and microstructural analysis of Strontium Rich $\left(\mathrm{Pb}_{x} \mathrm{~S}\right.$ $\left.\mathrm{r}_{1-x}\right) \mathrm{TiO}_{3}$ glass ceramics in Presence of $\mathrm{La}_{2} \mathrm{O}_{3}$," Advances in Materials Science and Engineering, vol. 2011, Article ID 747346, 9 pages, 2011.

[10] P. Yongping, Y. Wenhu, and C. Shoutian, "Influence of rare earths on electric properties and microstructure of barium titanate ceramics," Journal of Rare Earths, vol. 25, no. 1, pp. 154157, 2007.

[11] Z. Yao, H. Liu, Y. Liu et al., "Structure and dielectric behavior of Nd-doped $\mathrm{BaTiO}_{3}$ perovskites," Materials Chemistry and Physics, vol. 109, no. 2-3, pp. 475-481, 2008.
[12] R. Moos and K. H. Härdtl, "Defect chemistry of donor-doped and undoped strontium titanate ceramics between $1000^{\circ}$ and $1400^{\circ}$ C, Journal of the American Ceramic Society, vol. 80, no. 10, pp. 2549-2562, 1997.

[13] E. A. V. Ferri, J. C. Sczancoski, L. S. Cavalcante et al., "Photoluminescence behavior in $\mathrm{MgTiO}_{3}$ powders with vacancy/distorted clusters and octahedral tilting," Materials Chemistry and Physics, vol. 117, no. 1, pp. 192-198, 2009.

[14] M. Boulos, S. Guillemet-Fritsch, F. Mathieu, B. Durand, T. Lebey, and V. Bley, "Hydrothermal synthesis of nanosized $\mathrm{BaTiO}_{3}$ powders and dielectric properties of corresponding ceramics," Solid State Ionics, vol. 176, no. 13-14, pp. 1301-1309, 2005.

[15] C. Mao, X. Dong, T. Zeng, G. Wang, and S. Chen, "Formation and control of mechanism for the preparation of ultra-fine barium strontium titanate powders by the citrate precursor method," Materials Research Bulletin, vol. 42, no. 9, pp. 16021610, 2007.

[16] H.-Y. Tian, W.-G. Luo, X.-H. Pu, P.-S. Qiu, X.-Y. He, and A.L. Ding, "Synthesis and analyses of thermal decomposition and microstructure of Sr-doped barium titanate alkoxide derived precipitates and thin films," Thermochimica Acta, vol. 360, no. 1, pp. 57-62, 2000.

[17] F. Baeten, B. Derks, W. Coppens, and E. van Kleef, "Barium titanate characterization by differential scanning calorimetry," Journal of the European Ceramic Society, vol. 26, no. 4-5, pp. 589-592, 2006.

[18] J. J. Bian and Y. Z. Li, "Structural evolution and microwave dielectric properties of A-site deficient perovskite $\mathrm{La}_{(1-x) / 3} \mathrm{Na}_{x} \mathrm{NbO}_{3}(0.0<x \leq 0.4)$," Materials Chemistry and Physics, vol. 122, no. 2-3, pp. 617-622, 2010.

[19] L. S. Cavalcante, A. Z. Simões, J. W. M. Espinosa et al., "Study of structural evolution and photoluminescent properties at room temperature of $\mathrm{Ca}(\mathrm{Zr}, \mathrm{Ti}) \mathrm{O}_{3}$ powders," Journal of Alloys and Compounds, vol. 464, no. 1-2, pp. 340-346, 2008.

[20] L. S. Cavalcante, J. C. Sczancoski, J. W. M. Espinosa et al., "Intense blue and green photoluminescence emissions at room temperature in barium zirconate powders," Journal of Alloys and Compounds, vol. 471, no. 1-2, pp. 253-258, 2009.

[21] V. M. Longo, A. T. de Figueiredo, S. de Lázaro et al., "Structural conditions that leads to photoluminescence emission in $\mathrm{SrTiO}_{3}$ : an experimental and theoretical approach," Journal of Applied Physics, vol. 104, no. 2, Article ID 023515, 2008.

[22] S. K. Rout, L. S. Cavalcante, J. C. Sczancoski et al., "Photoluminescence property of $\mathrm{Ba}\left(\mathrm{Zr}_{0.25} \mathrm{Ti}_{0.75}\right) \mathrm{O}_{3}$ powders prepared by solid state reaction and polymeric precursor method," Physica B, vol. 404, no. 20, pp. 3341-3347, 2009.

[23] L. S. Cavalcante, J. C. Sczancoski, V. M. Longo et al., "Intense violet-blue photoluminescence in $\mathrm{BaZrO}_{3}$ powders: a theoretical and experimental investigation of structural order-disorder," Optics Communications, vol. 281, no. 14, pp. 3715-3720, 2008.

[24] V. M. Longo, L. S. Cavalcante, R. Erlo et al., "Strong violetblue light photoluminescence emission at room temperature in $\mathrm{SrZrO}_{3}$ : joint experimental and theoretical study," Acta Materialia, vol. 56, no. 10, pp. 2191-2202, 2008.

[25] M. Ganguly, S. K. Rout, W. S. Woo, C. W. Ahn, and I. W. Kim, "Characterization of A-site deficient samarium doped barium titanate," Physica B, vol. 411, pp. 26-34, 2013.

[26] T. Tubchareon, S. Soisuwan, S. Ratanathammaphan, and P. Praserthdam, "Effect of carbon-dopant on the optical band gap and photoluminescence properties of $\left[\mathrm{Ba}_{0.5} \mathrm{Sr}_{0.5}\right] \mathrm{TiO}_{3}$ powders 
synthesized by the sol-gel process," Journal of Luminescence, vol. 145, pp. 919-924, 2014.

[27] P. Bomlai, N. Sirikulrat, and T. Tunkasiri, "Effect of heating rate on the properties of $\mathrm{Sb}$ and $\mathrm{Mn}$-doped barium strontium titanate PTCR ceramics," Materials Letters, vol. 59, no. 1, pp. 118122, 2005.

[28] S. Schaab, M. Schulz, H. Fritze et al., "Influence of reducing atmosphere on the defect chemistry of lead lanthanum zirconate titanate (8/65/35)," Solid State Ionics, vol. 228, pp. 56-63, 2012.

[29] S. H. Yoon, S. H. Kwon, and K. H. Hur, "Dielectric relaxation behavior of acceptor (Mg)-doped $\mathrm{BaTiO}_{3}$," Journal of Applied Physics, vol. 109, pp. 084117-084118, 2011.

[30] S. Steinsvik, Y. Larring, and T. Norby, "Hydrogen ion conduction in iron-substituted strontium titanate, $\mathrm{SrTi}_{1-x} \mathrm{Fe}_{x} \mathrm{O}_{3-x / 2}(0$ $\leq \mathrm{x} \leq$ 0.8)," Solid State Ionics, vol. 143, no. 1, pp. 103-116, 2001.

[31] T. Kolodiazhnyi and A. Petric, "Analysis of point defects in polycrystalline $\mathrm{BaTiO}_{3}$ by electron paramagnetic resonance," Journal of Physics and Chemistry of Solids, vol. 64, no. 6, pp. 953960, 2003.

[32] M. S. Castro, W. Salgueiro, and A. Somoza, "Electron paramagnetic resonance and positron annihilation study of the compensation mechanisms in donor-doped $\mathrm{BaTiO}_{3}$ ceramics," Journal of Physics and Chemistry of Solids, vol. 68, no. 7, pp. 13151323, 2007.

[33] X. Zhao, Q. Yang, and J. Cui, "XPS study of surface absorbed oxygen of $\mathrm{ABO}_{3}$ mixed oxides," Journal of Rare Earths, vol. 26, no. 4, pp. 511-514, 2008.

[34] Q. Xu, D.-P. Huang, W. Chen, H. Wang, B.-T. Wang, and R.Z. Yuan, "X-ray photoelectron spectroscopy investigation on chemical states of oxygen on surfaces of mixed electronic-ionic conducting $\mathrm{La}_{0.6} \mathrm{Sr}_{0.4} \mathrm{Co}_{1-y} \mathrm{Fe}_{y} \mathrm{O}_{3}$ ceramics," Applied Surface Science, vol. 228, no. 1-4, pp. 110-114, 2004.

[35] N. A. Merino, B. P. Barbero, P. Eloy, and L. E. Cadús, " $\mathrm{La}_{1-x} \mathrm{Ca}_{x} \mathrm{CoO}_{3}$ perovskite-type oxides: identification of the surface oxygen species by XPS," Applied Surface Science, vol. 253, no. 3, pp. 1489-1493, 2006.

[36] W.-D. Yang, "PZT/PLZT ceramics prepared by hydrolysis and condensation of acetate precursors," Ceramics International, vol. 27, no. 4, pp. 373-384, 2001.

[37] Y. Song, F. Wang, Z. Jiang, and Y. Zhou, "Effect of $\mathrm{BaTi}_{4} \mathrm{O}_{9}$ fibers on dielectric properties of $0.64 \mathrm{BaTi}_{4} \mathrm{O}_{9}+0.36 \mathrm{BaPr}_{2} \mathrm{Ti}_{4} \mathrm{O}_{12}$ composites," Ceramics International, vol. 28, no. 6, pp. 685-688, 2002.

[38] J. X. Liao, C. R. Yang, J. H. Zhang, C. L. Fu, H. W. Chen, and W. J. Leng, "The interfacial structures of $(\mathrm{Ba}, \mathrm{Sr}) \mathrm{TiO}_{3}$ films deposited by radio frequency magnetron sputtering," Applied Surface Science, vol. 252, no. 20, pp. 7407-7414, 2006.

[39] W. H. Zhang, L. Chen, Y. T. Tao, W. H. Zhang, J. Chen, and J. X. Zhang, "Raman study of barium titanate with oxygen vacancies," Physica B, vol. 406, no. 24, pp. 4630-4633, 2011.

[40] R. Polini, A. Falsetti, E. Traversa, O. Schäf, and P. Knauth, "Solgel synthesis, $\mathrm{X}$-ray photoelectron spectroscopy and electrical conductivity of Co-doped ( $\mathrm{La}, \mathrm{Sr})(\mathrm{Ga}, \mathrm{Mg}) \mathrm{O}_{3-\delta}$ perovskites," Journal of the European Ceramic Society, vol. 27, no. 13-15, pp. 4291-4296, 2007.

[41] N. Lakshminarayanan, H. Choi, J. N. Kuhn, and U. S. Ozkan, "Effect of additional B-site transition metal doping on oxygen transport and activation characteristics in
$\mathrm{La}_{0.6} \mathrm{Sr}_{0.4}\left(\mathrm{Co}_{0.18} \mathrm{Fe}_{0.72} \mathrm{X}_{0.1}\right) \mathrm{O}_{3-\delta}$ (where $\mathrm{X}=\mathrm{Zn}$, Ni or $\mathrm{Cu}$ ) perovskite oxides," Applied Catalysis B, vol. 103, no. 3-4, pp. 318325, 2011.

[42] D.R. Lide, Handbook of Chemistry and Physics, 84th edition, 2004. 

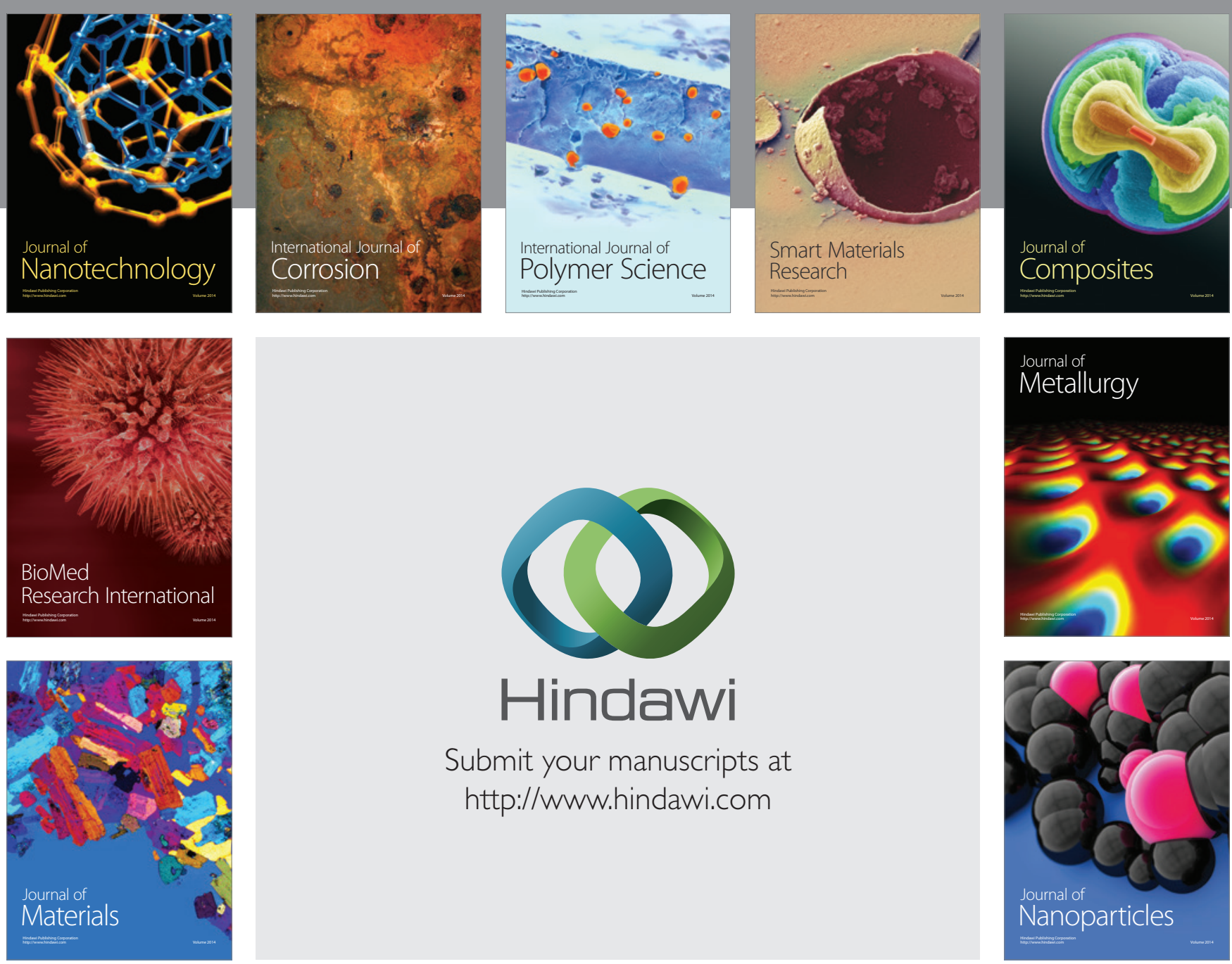

Submit your manuscripts at http://www.hindawi.com
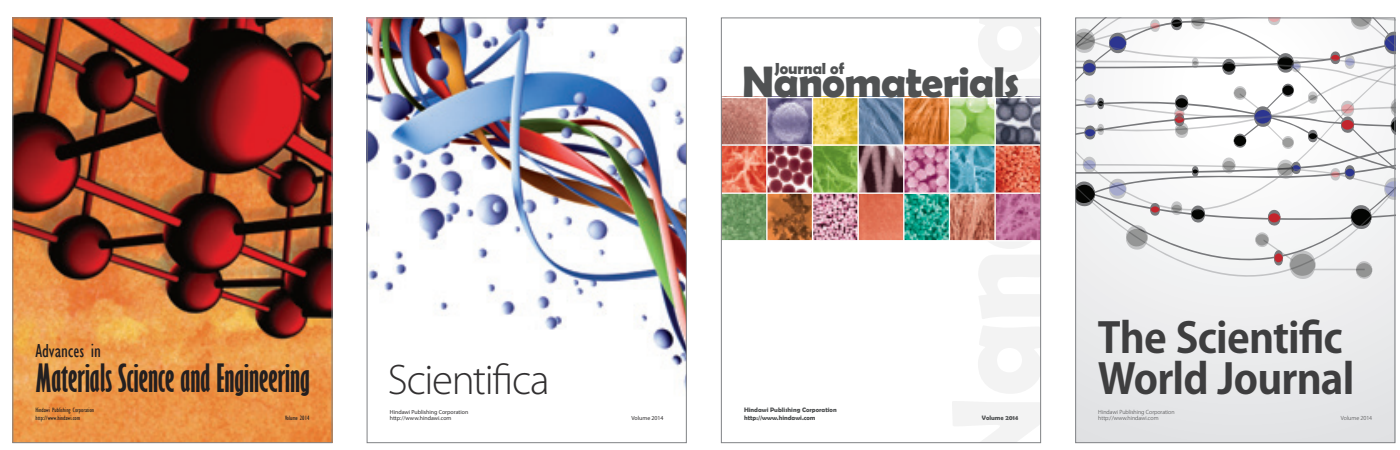

\section{The Scientific World Journal}
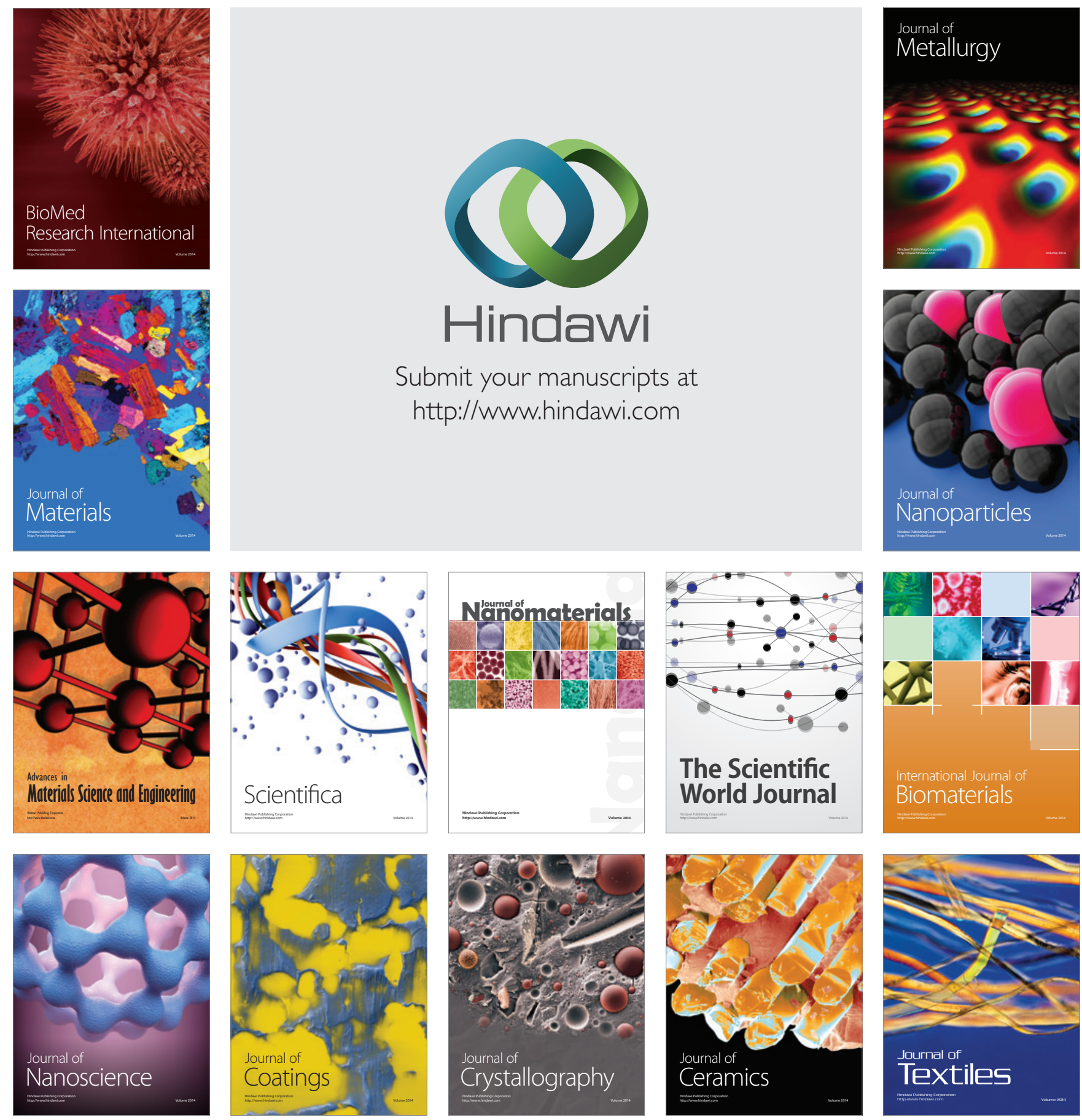